ARTICLE

Received 19 Dec 2014 | Accepted 13 Mar 2015 | Published 21 Apr 2015

DOI: $10.1038 /$ ncomms7925

OPEN

\title{
Designer diatom episomes delivered by bacterial conjugation
}

Bogumil J. Karas ${ }^{1, \dagger}$, Rachel E. Diner ${ }^{2,3}$, Stephane C. Lefebvre ${ }^{2}$, Jeff McQuaid ${ }^{2}$, Alex P.R. Phillips ${ }^{1}$, Chari M. Noddings', John K. Brunson', Ruben E. Valas², Thomas J. Deerinck ${ }^{4}$, Jelena Jablanovic ${ }^{2}$, Jeroen T.F. Gillard ${ }^{2}$, Karen Beeri ${ }^{2}$, Mark H. Ellisman ${ }^{4}$, John I. Glass', Clyde A. Hutchison III', Hamilton O. Smith, J. Craig Venter ${ }^{1,2}$, Andrew E. Allen ${ }^{2,3}$, Christopher L. Dupont ${ }^{2} \&$ Philip D. Weyman $^{1}$

Eukaryotic microalgae hold great promise for the bioproduction of fuels and higher value chemicals. However, compared with model genetic organisms such as Escherichia coli and Saccharomyces cerevisiae, characterization of the complex biology and biochemistry of algae and strain improvement has been hampered by the inefficient genetic tools. To date, many algal species are transformable only via particle bombardment, and the introduced DNA is integrated randomly into the nuclear genome. Here we describe the first nuclear episomal vector for diatoms and a plasmid delivery method via conjugation from Escherichia coli to the diatoms Phaeodactylum tricornutum and Thalassiosira pseudonana. We identify a yeast-derived sequence that enables stable episome replication in these diatoms even in the absence of antibiotic selection and show that episomes are maintained as closed circles at copy number equivalent to native chromosomes. This highly efficient genetic system facilitates high-throughput functional characterization of algal genes and accelerates molecular phytoplankton research.

\footnotetext{
${ }^{1}$ Synthetic Biology and Bioenergy Group, J. Craig Venter Institute, La Jolla, California 92037, USA. ${ }^{2}$ Microbial and Environmental Genomics Group, J. Craig Venter Institute, La Jolla, California 92037, USA. ${ }^{3}$ Integrative Oceanography Division, Scripps Institution of Oceanography, University of California San Diego, La Jolla, California 92037, USA. ${ }^{4}$ National Center for Microscopy and Imaging Research, University of California, San Diego, La Jolla, California 92093, USA. $\dagger$ Present address: Designer Microbes Inc., London, Ontario, Canada. Correspondence and requests for materials should be addressed to P.D.W. (email: pweyman@jcvi.org).
} 
$\mathrm{D}$ iatoms are eukaryotic phytoplankton that contribute a significant fraction of global primary productivity and demonstrate great potential for autotrophic bioproduction of fuels and higher value chemicals ${ }^{1-3}$. Although methods for genetic manipulation currently exist for some diatom species ${ }^{4-8}$, they are slow compared with the efficient methods available for other model microbes such as E. coli and yeast, and this has stymied both basic diatom research and applied strain development. To accelerate research in ecologically and biotechnologically important microalgae, we sought to develop diatom episomal vectors and improved transformation methods.

Circular DNA molecules have been previously isolated from diatoms, but they have never been successfully reintroduced as episomes ${ }^{9,10}$. This is unfortunate because episomes provide a reliable, consistent and predictable platform for protein expression by avoiding the complications of random chromosomal integration including multiple insertions, position-specific effects on expression and potential knockout of non-targeted genes ${ }^{4,7,8}$. Consistent protein expression from episomes may allow for efficient complementation experiments of diatom mutants made with recently developed TALEN technology ${ }^{11,12}$.

Episomes can be efficiently moved among bacteria and even between bacteria and eukaryotes via conjugation. Reports of transkingdom conjugation in other systems ${ }^{13-16}$ motivated us to explore direct conjugation of DNA into the pennate diatom Phaeodactylum tricornutum as an alternative to biolistic transformation methods that are standard for many diatom species $^{4-6}$. A conjugative link from Escherichia coli to diatoms streamlines the genetic manipulation workflow for diatoms. Plasmids can be assembled and manipulated in vitro before being introduced in E. coli for direct conjugative transfer to diatoms, thus eliminating the need for time-consuming, high-yield plasmid DNA preparations and access to expensive specific equipment and reagents (for example, gene gun). In conjugative systems, a two-plasmid system is often used where a conjugative plasmid (for example, RP4/RK2 or its derivatives such as pTA-MOB ${ }^{17}$ ) contains all of the genes required for establishing a conjugative bridge between the donor and recipient cell and a cargo plasmid contains the construct of interest. Inclusion of an origin of transfer (oriT) on the cargo plasmid allows it to be mobilized to the recipient by proteins encoded on the conjugative plasmid. Maintenance of the cargo plasmid as an episome in the recipient cell further requires the presence of sequences that permit replication and segregation of the DNA molecule.

In this paper we describe our approach to identify a DNA sequence that can support episomal replication in the diatoms Phaeodactylum tricornutum and Thalassiosira pseudonana. Although we had initially intended to isolate a P. tricornutum sequence that supported episome replication in diatoms, we identified a sequence encoded by a yeast-derived sequence on the cloning vector that performed this function. We further developed a conjugation-based method to directly transfer episomes from E. coli to diatoms. These novel tools and methods compose an efficient and high-throughput system for diatom genetic manipulation that will enable rapid and fundamental advances in diatom functional genetics.

\section{Results}

Design of episomal vectors. To develop an extra-chromosomal replicating vector for diatoms, we first isolated a sequence that functions as a centromere or origin of replication in $P$. tricornutum ${ }^{18,19}$. Classical centromere signatures, based on DNA composition ${ }^{20-22}$, are absent from putative full-length $P$. tricornutum chromosomes. Therefore, we implemented an experimental workflow based on iterative transformation of $P$. tricornutum with large, cloned fragments $(24-94 \mathrm{~kb})$ of scaffold 25 (Fig. 1a), which is fully assembled between telomeres. Molecules maintained as episomes in P. tricornutum could be extracted and successfully reintroduced into $E$. coli by electroporation (a technique we define as 'episome rescue' henceforth). Episome rescue cycles were performed by (1) growing diatom exconjugant colonies in small liquid cultures, (2) extracting diatom DNA, (3) electroporating E. coli with the diatom DNA and (4) extracting and analysing plasmids from E. coli using standard techniques (Supplementary Fig. 1).

Several diatom colonies were obtained from transformations with the scaffold 25 fragments using electroporation- and polyethylene glycol (PEG)-mediated transformation methods to prevent shearing of the large plasmids. P. tricornutum transformation efficiency using the PEG-mediated methods was low and often yielded only one colony per transformation with an approximate efficiency of $1 \times 10^{-8}$. Of the episomes rescued from these colonies (Supplementary Fig. 1c), we chose to work with plasmids p0521o containing the P. tricornutum region 25-1, and a spontaneously minimized version, p0521o-reduced; both plasmids were rescued successfully after a second round of P. tricornutum transformation (Supplementary Fig. 1d,e). We modified plasmids p0521o and p0521o-reduced by adding a cloning site composed of the URA3 gene flanked by I-CeuI and I-SceI sites (see Supplementary Table 1 for primer sequences) and renamed them p0521 and p0521s, respectively. The additional URA3 marker provides an efficient counter selection to insert DNA sequences into the plasmids using yeast assembly methods.

Development of conjugation to diatoms. We improved the delivery of p0521 and p0521s to P. tricornutum by developing a conjugation-based method that transferred p0521s at an efficiency of $4.0 \times 10^{-4}$ diatom cells, significantly higher than our attempts at electroporation and PEG-mediated transformation (Supplementary Table 2), and higher than reported electroporation ${ }^{23}$ and particle bombardment ${ }^{6}$ efficiencies $\left(4.5 \times 10^{-5}-10^{-7}\right)$. Transkingdom conjugation has been demonstrated previously for yeasts and mammalian cells ${ }^{13-16}$, but never before in the Stramenopile lineage. To verify that conjugation was the mechanism of gene transfer, we performed two important controls. First, phleomycin-resistant $P$. tricornutum colonies were only obtained when E. coli contained the conjugative plasmid (RP4 variant pRL443 (ref. 24)), and second, the origin of transfer (oriT) on the mobilizable cargo plasmid (for example, p0521s) was essential to obtain phleomycin-resistant P. tricornutum colonies (Fig. 1b). Physical association between E. coli and diatoms, a necessary prerequisite for conjugation, was identified by scanning electron microscope analysis (Supplementary Fig. 2).

We verified that rescued episomes were from $P$. tricornutum and not from possible leftover $E$. coli used during the conjugation process. Streaking $P$. tricornutum exconjugant cultures on LB plates and incubating at $37^{\circ} \mathrm{C}$ did not yield any E. coli colonies. This effectively confirmed that E. coli culture containing the plasmid donor was eliminated during selection of $P$. tricornutum exconjugants. After episome rescue, $\sim 30 \%$ of $P$. tricornutum lines yielded plasmids of the same size as the original starting plasmid (Supplementary Fig. 3). We identified one class of incorrectly sized plasmids as chimeras between the conjugative and the cargo plasmids (RP4 and p0521s, respectively). Chimeras resulting from multiple copies of oriT have been previously noted $^{17}$, and we later eliminated them by using a variant of the RP4 conjugative plasmid lacking oriT ( pTA-MOB $^{17}$ ). A second class of incorrectly sized plasmids was occasionally recovered 
with minor size differences (Supplementary Fig. 3). Although sequencing of several plasmids identified small deletions and a retrotransposon element insertion event (Supplementary Fig. 4), plasmids were stably maintained once identified as having the correct size as discussed below.

DNA sequence conferring episomal replication in diatoms. To identify the elements of p0521s allowing replication in diatoms, we engineered several variants either lacking the $P$. tricornutumderived region or lacking other components of the plasmid. First, we mapped the $2.5-\mathrm{kb} P$. tricornutum sequence in p0521s to two distinct subfragments within fragment 25-1 (Fig. 1a). Compared with conjugation with the full-length p05201s plasmid, deletion of either of the two subfragments (R1 or R2) that make up the $2.5-\mathrm{kb}$ region led to approximately half as many $P$. tricornutum exconjugants per mating (Fig. 1b). Surprisingly, complete removal of the $P$. tricornutum-derived region still yielded exconjugants at high efficiency (Fig. 1b), although plasmid p0521s containing the region yielded $\sim 2.5$-fold more exconjugants than the version with the $P$. tricornutum sequence deleted. Similar numbers of correctly sized plasmids were rescued regardless of the presence of the $P$. tricornutum region $(7 / 20$ or $8 / 20$ for p0521s or p0521s- $\Delta$ R1R2, respectively)(Supplementary Fig. 3 and Supplementary Table 3). Thus, while P. tricornutum fragments increased conjugation efficiency modestly, they were not essential for this process and therefore, another sequence on the cargo plasmid was responsible for replication in P. tricornutum.
To identify the non-diatom sequence responsible for replication in P. tricornutum, we varied three possible regions of the p0521s plasmid: the bacterial maintenance region and plasmid backbone, the yeast maintenance region (CEN6-ARSH4-HIS3), and the $P$. tricornutum-derived region. We tested the influence of the bacterial maintenance region from p0521s (that is, pCC1BAC) by replacing it with the pUC19 plasmid backbone, and used this bacterial replication origin together with the P. tricornutum ShBle cassette and oriT sequence to make the four test plasmids pPtPucl through pPtPuc4 (Fig. 1c). The yeast maintenance region was cloned in plasmids pPtPucl and 3 , the $P$. tricornutum-derived region was cloned in plasmids pPtPucl and 2, and the final plasmid, pPtPuc4, contained only the bacterial maintenance region from pUC19 with the oriT and ShBle cassette for phleomycin resistance in P. tricornutum.

P. tricornutum exconjugants were obtained for all four pPtPuc plasmids; however, pPtPuc1 and pPtPuc3, both containing the yeast maintenance region, CEN6-ARSH4-HIS3, yielded over 30 -fold more colonies than pPtPuc2 and pPtPuc4 (Fig. 1c and Supplementary Table 3). Episome rescue was successful for 20/20 and 19/20 P. tricornutum pPtPucl and pPtPuc3 colonies, respectively. No episomes could be rescued from $P$. tricornutum pPtPuc2 and pPtPuc4 exconjugants; phleomycin-resistant colonies obtained with these plasmids were likely the result of chromosomal integration. This result was consistent with the 1.4-kb CEN6-ARSH4-HIS3 fragment (present on plasmids pPtPuc1 and pPtPuc3) containing a sequence establishing episomal replication in P. tricornutum. When rescued episomes a

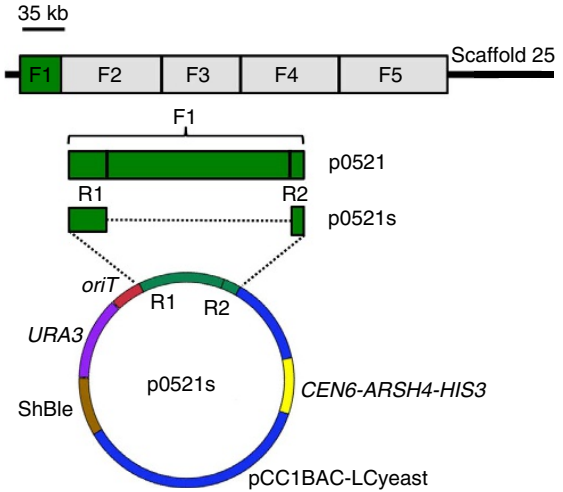

C

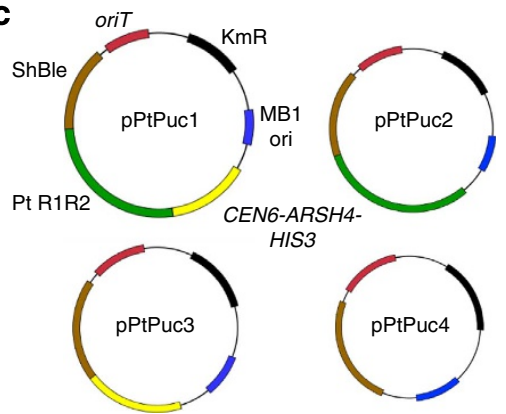

b
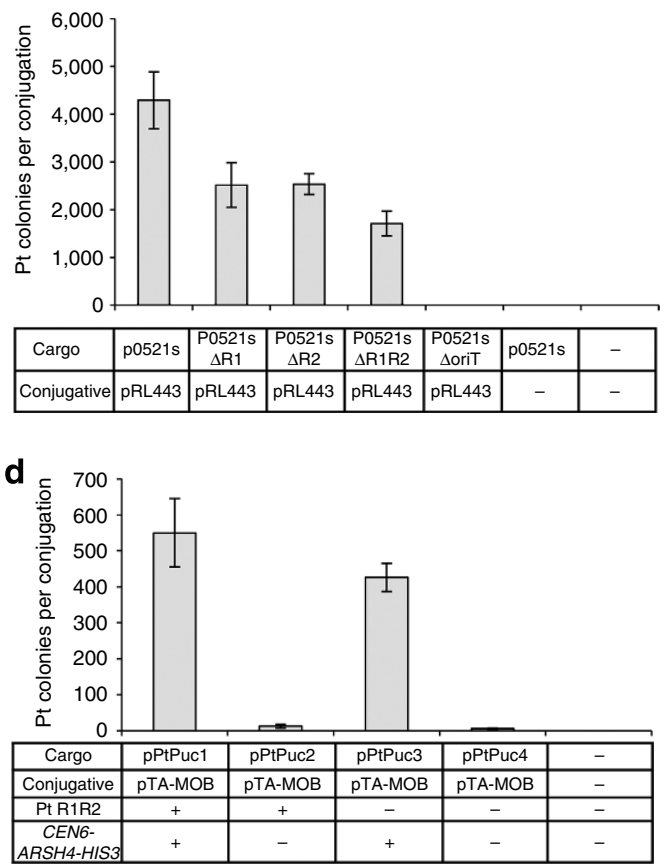

Figure 1 | Conjugative transfer of plasmids from E. coli to P. tricornutum. (a) Map of the plasmids p0521 and p0521s and their derivation from P. tricornutum scaffold 25. OriT, origin of transfer; URA3, gene encoding orotidine $5^{\prime}$-phosphate decarboxylase from S. cerevisiae, and ShBle, phleomycinresistance cassette with $P$. tricornutum FcpF promoter and FcpA terminator. (b) Average number of $P$. tricornutum colonies obtained per conjugation for different 'cargo' plasmid variants of p0521s. Deletions of features indicated by $\Delta$, pRL443 is the RP4 conjugative plasmid. (c) Maps of plasmids used to test the importance of the $P$. tricornutum- and yeast-derived regions. Plasmids pPtPuc1-4 differ in whether they have the $P$. tricornutum-derived region from p0521s (Pt R1R2, green) or the yeast-derived CEN6-ARSH4-HIS3 (yellow). Other plasmid features present in all four plasmids are described on the pPtPuc1 map. (d) Number of $P$. tricornutum colonies obtained after conjugation with the pPtPuc plasmids ('cargo' plasmids). Features of each plasmid are noted in the table under the figure (for example, the P. tricornutum-derived region from p0521S, Pt R1R2, or the yeast elements, CEN6-ARSH4-HIS3). Error bars denote one s.d. of the mean from at least three biological replicates per experiment. 
a

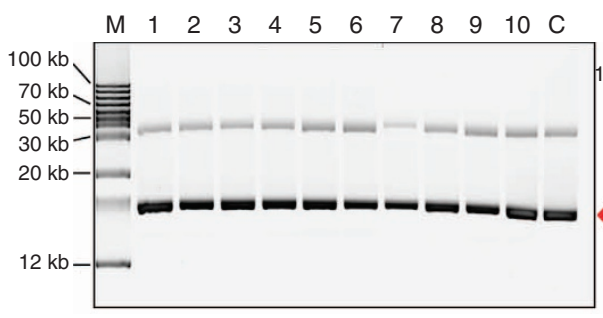

b $\begin{array}{llllllllllll}M & 1 & 2 & 3 & 4 & 5 & 6 & 7 & 8 & 9 & 10 & \mathrm{C}\end{array}$

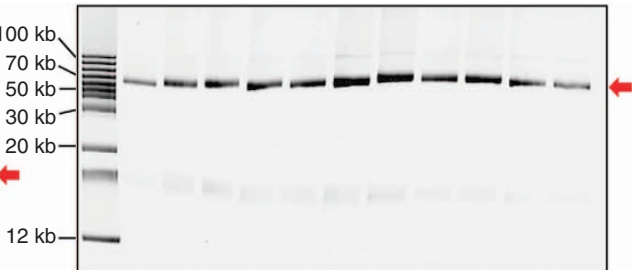

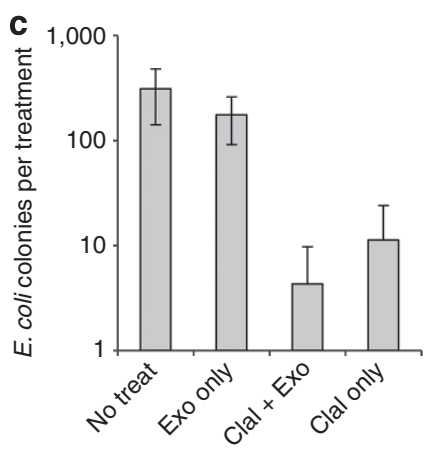

d

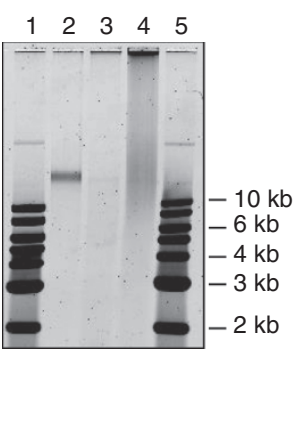

e

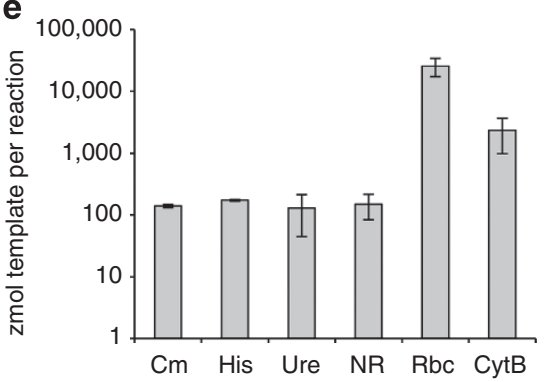

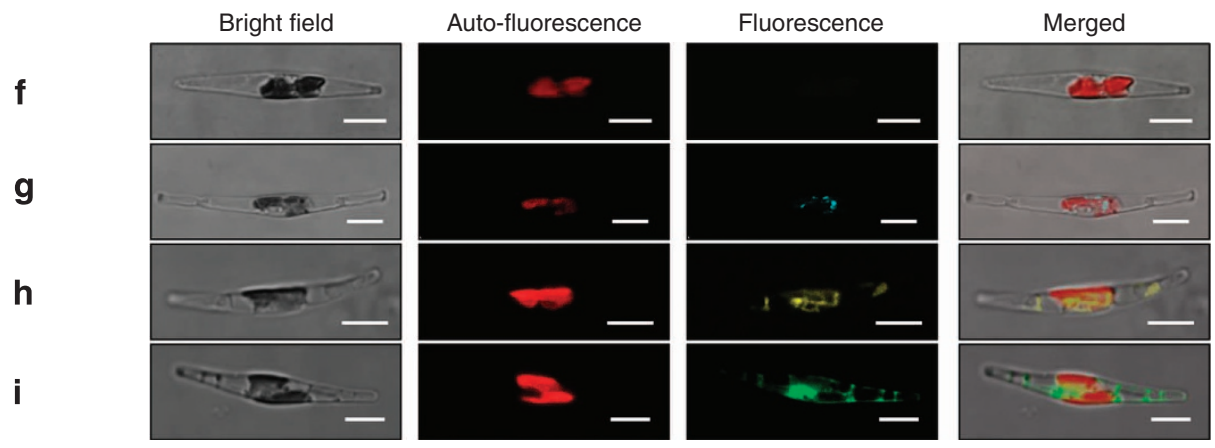

Figure 2 | Demonstration that $\boldsymbol{P}$. tricornutum episomes replicate as stable, circular, low-copy plasmids (a-e), and expression and localization of proteins encoded on the $\boldsymbol{P}$. tricornutum episome p0521s (F-I). (a) Cultures of P. tricornutum containing p0521s (clone 9, Supplementary Fig. 3), were subcultured in seawater medium for 28 days with or without antibiotic selection and plated (Supplementary Fig. 5). DNA from five antibiotic-resistant colonies from each culture (Supplementary Fig. 5D) was recovered in E. coli and isolated plasmids were separated by agarose gel electrophoresis. Shown are rescued plasmids derived from separate $P$. tricornutum colonies that were initially subcultured for 28 days without (lanes 1-5) or with (lanes 6-10) antibiotic selection. ' $\mathrm{M}$ ' designates supercoiled marker ${ }^{41}$ and ' $C$ ' designates the original plasmid (isolated from clone 9 ) introduced into $P$. tricornutum. Arrow denotes supercoiled plasmid band. (b) Stability of p0521-Se containing a 49-kb S. elongatus fragment. Ten independently transformed $P$. tricornutum lines containing p0521-Se were subcultured in liquid media with selection for 60 days, followed by episome rescue and separation of plasmids by agarose gel electrophoresis. Arrow denotes supercoiled plasmid band. (c) Plasmids extracted from P. tricornutum were untreated, treated with exonuclease, Clal endonuclease or a combination of exonuclease and Clal. Treated plasmids were transformed into $E$. coli and the number of transformed colonies was plotted (error bars indicate one s.d. of the mean from three biological replicates). (d) Agarose gel electrophoresis of plasmids extracted from $P$. tricornutum and treated with nucleases. Lanes from left to right: (1) $1 \mathrm{~kb}+$ ladder (NEB), (2) p0521s control (from E. coli), (3) p0521s exonuclease-treated (extracted from P. tricornutum), (4) p0521s untreated (extracted from P. tricornutum), (5) $1 \mathrm{~kb}+$ ladder (NEB), (e) Copy number of p0521s in P. tricornutum determined by qPCR. Cm (Cat gene) and His (HIS3 gene) are loci found on the episome backbone; Ure (urease, protein ID 29702) and NR (nitrate reductase, protein ID 54983) are loci encoded on P. tricornutum nuclear chromosomes 18 and 20, respectively; Rbc (RuBisCO small subunit) and CytB (Cytochromoe B) are loci found on the P. tricornutum chloroplast and mitochondrial chromosomes, respectively. Error bars denote one s.d. of the mean from three biological replicates. (f) Wild-type P. tricornutum, fluorescence measured with GFP settings. (g) P. tricornutum expressing CFP translationally fused to beta-carbonic anhydrase (Protein ID 51305) localized to the chloroplast pyrenoid encoded on plasmid p0521s. (h) P. tricornutum expressing YFP translationally fused to mitochondrial urea transporter (Protein ID 39772) encoded on plasmid p0521s. (i) P. tricornutum expressing GFP localized to the cytoplasm encoded on plasmid p0521s. Scale bar for $\mathbf{f}-\mathbf{i}$ indicates $5 \mu \mathrm{m}$.

from pPtPuc1 and pPtPuc3 were analysed by gel electrophoresis, $8 / 20$ and $10 / 20$, respectively, had sizes identical to the original material used to conjugate $P$. tricornutum. Thus, the originally isolated P. tricornutum sequence found in p0521s (that is, R1 and R2) was not essential for episomal replication in P. tricornutum, and the vector-derived sequence, CEN6-ARSH4-HIS3, was sufficient to establish replicating episomes. Determining how the CEN6-ARSH4-HIS3 fragment confers episomal replication is the subject of ongoing research.
Characteristics of episome replication in diatoms. Once the episomes were established in the diatom cell, they were maintained with high fidelity. In the absence of selection after an estimated 30 generations, an average of $35 \%$ of the cells retained the p0521s plasmid corresponding to a segregation efficiency of 97\% (Fig. 2a, Supplementary Table 4, Supplementary Fig. 5). We were also successful in maintaining a $49-\mathrm{kb}$ heterologous sequence from the cyanobacterium Synechococcus elongatus on the episome at the correct size (p0521-Se, Fig. 2b) for two months 

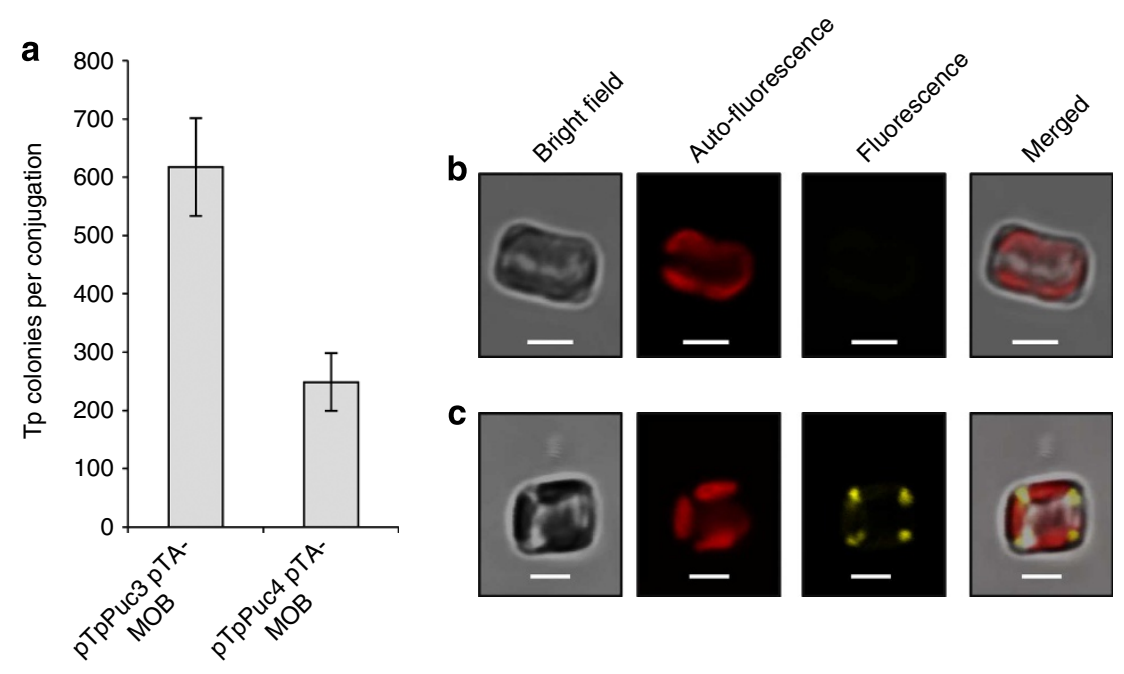

Figure 3 | Episome replication in T. pseudonana. (a) Conjugation from E. coli to T. pseudonana results in increased conjugation efficiency when the yeast CEN6-ARSH4-HIS3 region is included on the plasmid (pTpPuc3) compared with control plasmid lacking this region (pTpPuc4). Error bars denote one s.d. of the mean from at least three biological replicates. $(\mathbf{b}, \mathbf{c})$ Images of $T$. pseudonana wild type (b) and exconjugants expressing YFP translationally fused to PEPCK (Protein ID_5186) encoded on a p0521s-derived episome (c). Scale bar, $2.5 \mu \mathrm{m}$.

in the presence of the antibiotic zeocin. Episomes (p0521s and p0521) were maintained in $P$. tricornutum in closed circular form as determined by exonuclease treatment on extracted $P$. tricornutum DNA before episome rescue (Fig. 2c,d, Supplementary Fig. 6). Southern blot analysis in which DNA was extracted from $P$. tricornutum p0521s-containing lines also supported circular replication and absence of genomic integration (Supplementary Fig. 7). Finally, quantitative PCR (qPCR) assays supported maintenance of the episome at native chromosomal copy number in P. tricornutum (Fig. 2e, Supplementary Fig. 6). The biotechnological utility of the diatom episome was tested by expressing multiple fusions of fluorescent proteins with proteins of known localization ${ }^{23,25,26}$ (Fig. 2f-i). Altogether, the data is consistent with p0521s maintained as a stable, circular, episome replicating at a similar copy number as native nuclear $P$. tricornutum chromosomes, allowing for efficient protein expression.

Extension of methods to a centric diatom. We further investigated if our system for genetic manipulation of $P$. tricornutum could be transposed to the centric diatom $T$. pseudonana that has fully silicified shell. Episomes were modified to have the nourseothricin antibiotic selectable marker cassette that functions in T. pseudonana. Using a variant of plasmid pPtPuc3 that we called pTpPuc3, we successfully conjugated the episome into T. pseudonana with an efficiency of $2.0 \times 10^{-4}$ diatom cells (Fig. 3). While plasmids with the CEN6-ARSH4-HIS3 region (pTpPuc3) or without (pTpPuc4) both yielded T. pseudonana colonies, only the pTpPuc3 episome could be successfully rescued consistent with the yeast sequence conferring episomal replication ability in T. pseudonana. Plasmids recovered after episome rescue from $T$. pseudonana were identical in size to the original plasmid control (Supplementary Fig. 8 and Supplementary Table 3). We constructed a version of p0521s that had the nourseothricin resistance gene driven by a $T$. pseudonana promoter and that also encoded a translational fusion between yellow fluorescent protein (YFP) and T. pseudonana phosphoenolpyruvate carboxykinase (PEPCK). Introduction of this plasmid resulted in T. pseudonana exconjugants with highly visible YFP signal in the mitochondria as expected ${ }^{27,28}$ (Fig. 3). Altogether the results observed for $T$. pseudonana mirror the findings in $P$. tricornutum and established that the episome/conjugation system operates in a similar fashion in both diatom species.

\section{Discussion}

We discovered a small sequence $(1.4 \mathrm{~kb})$ from yeast that permits low-copy episomal replication in the diatoms $P$. tricornutum and T. pseudonana. This small yeast sequence (CEN6-ARSH4-HIS3) contains the plasmid maintenance functions for yeast centromeric plasmids (CEN6 and ARSH4) and the HIS3 gene to complement yeast histidine auxotrophy. We constructed two replicating plasmids for $P$. tricornutum, p0521s and pPtPuc3, and each contains the CEN6-ARSH4-HIS3 sequence. A plasmid identical to pPtPuc3, but with the antibiotic selection replaced with the T. pseudonana nourseothricin resistance cassette was also constructed (pTpPuc3). Plasmid p0521s has an ShBle cassette for $P$. tricornutum selection with phleomycin as well as the pCC1BAC backbone to support large inserts (up to several hundred kilobases) in E. coli. Cloning sequences of interest into this backbone can be performed using yeast assembly methods $^{29,30}$ and inserts can be designed to replace the URA3 gene with counter selection on 5-fluorooritic acid (5FOA; Fig. 4). When cloning genes of interest into p0521s using yeast assembly, predigestion of the plasmid with I-CeuI and I-SceI is recommended to increase the recombination efficiency. For expression of smaller sequences in P. tricornutum (for example, single-gene expression cassettes), pPtPuc3 is better suited with a smaller backbone that can be amplified by PCR and assembled with sequences of interest using Gibson assembly ${ }^{31}$. Note that the high copy number of pUC19-based plasmids may complicate cloning sequences larger than $\sim 10 \mathrm{~kb}$. To clone sequences into pPtPuc3, we typically insert sequences of interest immediately following the $3^{\prime}$ end of the CEN6-ARSH4-HIS3 region. Plasmid pTpPuc3 can be engineered with genes in a similar manner as described above for pPtPuc3. All three plasmids (p0521s, pPtPuc3 and pTpPuc3) are available at Addgene. Alternatively, the CEN6ARSH4-HIS3 region can simply be amplified and added to any plasmid to permit replication as an episome, provided a means of selection for transformed cells is also present on the plasmid (Fig. 4). Further inclusion of an oriT is necessary if introduction by conjugation is also desired. 
a

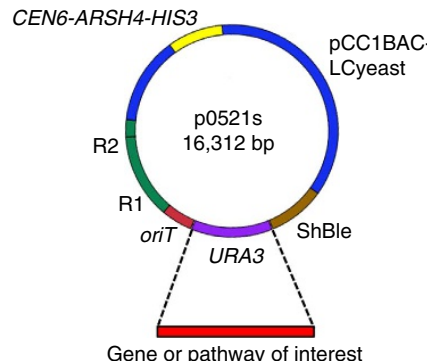

b

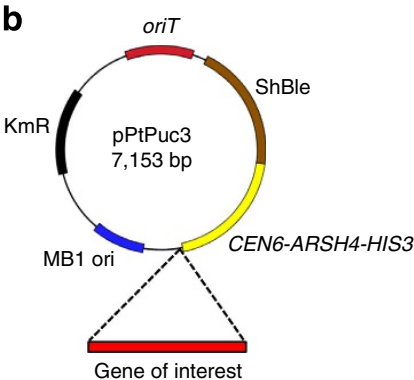

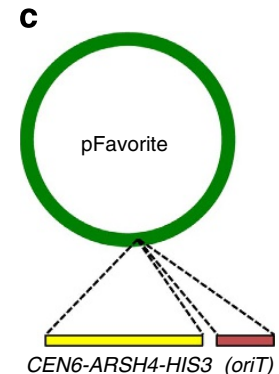

Figure 4 | Suggested strategies to clone sequences of interest into diatom episomes. (a) Genes or pathways of interest can be assembled into p0521s replacing the URA3 gene. Incoming DNA should be prepared with sequence overlaps to the plasmid regions flanking URA3 and assembled in yeast spheroplasts with counter-selection on 5FOA. (b) Smaller sequences interest (equivalent in size to single expression cassettes) can be assembled into pPtPuc3 using Gibson assembly or other cloning strategy. Sequences can be introduced anywhere in the plasmid, but we typically insert at the $3^{\prime}$ region of the CEN6-ARSH4-HIS3 sequence. (c) Any existing plasmid can be modified with the yeast CEN6-ARSH4-HIS3 sequence amplified from p0521s, pPtPuc3 or other source to enable episomal replication in P. tricornutum or T. pseudonana. The oriT sequence should also be included (if it is not already present in the vector sequence) if conjugation from $E$. coli is chosen as the method of plasmid introduction.

While our initial approach was to discover diatom DNA sequences that function as centromeres, the resulting finding that a yeast-derived sequence could function in a similar manner was surprising and could help elucidate native diatom centromere sequences and sequence requirements in ongoing research. Whether the yeast-derived sequence functions as a true centromere in diatoms remains to be tested. Although maintenance of the $P$. tricornutum episome without antibiotic selection was not as high as the $\sim 80-95 \%$ retention observed for yeast centromeric vectors $^{18}$, it is higher than yeast vectors based on replication origins (ARS) in which only $1 \%$ of cells maintain the plasmid in the absence of selection after an equivalent number of generations ${ }^{19}$. Furthermore, as noted for yeast ${ }^{29}$, most of the rearrangements of the diatom episome appear to occur during plasmid introduction; once a line was verified to have the correctly sized plasmid in P. tricornutum, the episome replicated without alteration over long periods of time (Fig. 2a, Supplementary Fig. 5). Interestingly, the CEN6 (13\% GC) and ARSH4 (30\% GC) regions have much lower GC content relative to the average for $P$. tricornutum (48\% GC). Low GC regions are known key features in red algal and other protist centromeres ${ }^{22,32}$ and may be functioning in a similar manner in P. tricornutum.

The diatom system described above is the second system (apart from yeasts ${ }^{13,16,33}$ ) in which an episome was introduced into a eukaryotic cell by conjugation and stably maintained. Conjugative delivery of such elements results in order of magnitude gains in efficiency over widely used particle bombardment methods ${ }^{6}$, both in time and materials, at the genetic manipulation and screening stages. In addition, a large DNA sequence $(49 \mathrm{~kb})$ was successfully introduced and maintained in P. tricornutum using this system, suggesting that an entire metabolic pathway could be introduced into the diatom, which may facilitate and accelerate biotechnological applications in these organisms. We observed great flexibility in the conditions that favour conjugation (Supplementary Table 2), but presented the optimum protocols that we have developed. For P. tricornutum, we found that diatom cells grown on agar plates were transformed by conjugation at a higher rate than liquid grown cells, while T. pseudonana cells were best grown in liquid culture due to difficulties growing this diatom on plates for extended periods. In adapting the technique to other diatom species, plasmids should minimally have the CEN6-ARSH4-HIS3 region, an origin of transfer (oriT) and a selectable marker functioning in the diatom of interest. Conditions during the conjugation $\left(60-90 \mathrm{~min}\right.$ at $30^{\circ} \mathrm{C}$ on $1 / 2$ strength $\mathrm{L} 1$ agar $+5 \% \mathrm{LB}$ medium) are a compromise between those optimal for E. coli ( $\mathrm{LB}$ agar, $37^{\circ} \mathrm{C}$ ) and those optimal for the diatom ( $\mathrm{L} 1$ medium, $18^{\circ} \mathrm{C}$ ) and will likely require empirical determination for other diatom species.

In addition to its biotechnological utility, bacterial conjugation to diatoms is interesting in light of the complex evolutionary history of the Stramenopile clade, which is characterized by multiple endosymbiotic events 34 and recent horizontal gene transfers from marine bacteria ${ }^{35,36}$. Diatom genomes contain a high percentage of recently transferred bacterial genes, and transkingdom conjugation may provide a possible mechanism to explain the acquisition of some of the bacterial DNA that makes up $5-10 \%$ of diatom genomes ${ }^{36}$. The results also add credence to the increasing awareness that conjugation influences microbial ecology in the oceans ${ }^{37-39}$.

The ease, simplicity and scalable nature of these novel tools makes them amenable to an efficient and high-throughput functional genetic system for diatoms. This system represents a new and exciting development to begin to make rapid and fundamental advances in gene function and to start understanding the molecular regulation controlling the biology of these globally significant marine phytoplankton species.

\section{Methods}

Microbial strains and growth conditions. Saccharomyces cerevisiae VL6-48 (ATCC MYA-3666: MAT $\alpha$ his3- 200 trp1- $\Delta 1$ ura3-52 lys2 ade2-1 met14 cir ${ }^{0}$ ) cells were grown in rich medium (YEPD) or complete minimal medium lacking histidine or histidine and uracil or histidine to which $1 \mathrm{gl}^{-1}$ of 5 -fluoroorotic acid (5FOA) was added (Teknova). In addition, $60 \mathrm{mgl}^{-1}$ adenine sulfate was added to all yeast media. All complete minimal media used for plating yeast cells directly after spheroplast transformation contained $1 \mathrm{M}$ Sorbitol.

Escherichia coli (Epi300, Epicentre) were grown on Luria broth or agar supplemented with chloramphenicol $\left(20 \mathrm{mgl}^{-1}\right)$ or kanamycin $\left(50 \mathrm{mgl}^{-1}\right)$ or ampicillin $\left(50 \mathrm{mgl}^{-1}\right)$ or tetracycline $\left(10 \mathrm{mgl}^{-1}\right)$ or gentamicin $\left(20 \mathrm{mgl}^{-1}\right)$ or combinations of these as needed.

E. coli strains containing plasmids p0521s (GenBank accession KP745602), pPtPuc3 (GenBank accession KP745601) and pTpPuc3 (GenBank accession KP745603) described in this manuscript have been deposited at Addgene.com and are available for request.

Phaeodactylum tricornutum was grown in $\mathrm{L} 1$ medium at $18^{\circ} \mathrm{C}$ under cool white fluorescent lights $\left(50 \mu \mathrm{E} \mathrm{m}^{-2} \mathrm{~s}^{-1}\right)$.

L1 medium. For liquid medium combine: 11 Aquil Salts (Synthetic Seawater), $2 \mathrm{ml} \mathrm{NP}$ stock, $1 \mathrm{ml} \mathrm{L1}$ trace metals stock, $0.5 \mathrm{ml} / 2$ vitamin solution. Filter sterilize through a $0.2-\mu \mathrm{m}$ filter. For agar plates, combine one part sterilized liquid L1 medium and one part autoclaved $2 \%$ Bacto agar and pour into petri dishes.

Aquil salts. (Two separate solutions, anhydrous and hydrous salts, are made at $2 \times$ strength and mixed to make Aquil salts).

Anhydrous salts. Anhydrous salts (resuspend in $500 \mathrm{ml}$ ): $\mathrm{NaCl} 24.5 \mathrm{~g}, \mathrm{Na}_{2} \mathrm{SO}_{4}$

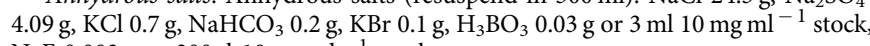
$\mathrm{NaF} 0.003 \mathrm{~g}$ or $300 \mathrm{ul} 10 \mathrm{mg} \mathrm{ml}^{-1}$ stock.

Hydrous salts. Hydrous salts (resuspend in $500 \mathrm{ml}$ ): $\mathrm{MgCl}_{2} 6 \mathrm{H}_{2} 011.1 \mathrm{~g}, \mathrm{CaCl}_{2}$ ${ }_{2} \mathrm{H}_{2} \mathrm{O} 1.54 \mathrm{~g}$. 
NP stock. $\mathrm{NaNO}_{3} 37.5 \mathrm{~g}$ per $100 \mathrm{ml}, \mathrm{NaH}_{2} \mathrm{PO}_{4}-\mathrm{H}_{2} \mathrm{O} 2.5 \mathrm{~g}$ per $100 \mathrm{ml}$.

L1 trace metals. Mix-up the following to make 11 at $1,000 \times$ (stock solutions in parentheses): $\mathrm{FeCl}_{3} \cdot 6 \mathrm{H}_{2} \mathrm{O} 3.15 \mathrm{~g}, \mathrm{Na}_{2} \mathrm{EDTA} \cdot 2 \mathrm{H}_{2} \mathrm{O} 4.36 \mathrm{~g}, \mathrm{CuSO}_{4} \cdot 5 \mathrm{H}_{2} \mathrm{O}$ $\left(9.8 \mathrm{gl}^{-1} \mathrm{dH}_{2} \mathrm{O}\right) 0.25 \mathrm{ml}, \mathrm{Na}_{2} \mathrm{MoO}_{4} \cdot 2 \mathrm{H}_{2} \mathrm{O}\left(6.3 \mathrm{gl}^{-1} \mathrm{dH}_{2} \mathrm{O}\right) 3.0 \mathrm{ml}, \mathrm{ZnSO}_{4} \cdot 7 \mathrm{H}_{2} \mathrm{O}$ $\left(22.0 \mathrm{gl}^{-1} \mathrm{dH}_{2} \mathrm{O}\right) 1.0 \mathrm{ml}, \mathrm{CoCl}_{2} \cdot 6 \mathrm{H}_{2} \mathrm{O}\left(10.0 \mathrm{gl}^{-1} \mathrm{dH}_{2} \mathrm{O}\right) 1.0 \mathrm{ml}, \mathrm{MnCl}_{2} \cdot 4 \mathrm{H}_{2} \mathrm{O}$ $\left(180.0 \mathrm{gl}^{-1} \mathrm{dH}_{2} \mathrm{O}\right) 1.0 \mathrm{ml}, \mathrm{H}_{2} \mathrm{SeO}_{3}\left(1.3 \mathrm{gl}^{-1} \mathrm{dH}_{2} \mathrm{O}\right) 1.0 \mathrm{ml}, \mathrm{NiSO}_{4} \cdot 6 \mathrm{H}_{2} \mathrm{O}$ $\left(2.7 \mathrm{gl}^{-1} \mathrm{dH}_{2} \mathrm{O}\right) 1.0 \mathrm{ml}, \mathrm{Na}_{3} \mathrm{VO}_{4}\left(1.84 \mathrm{gl}^{-1} \mathrm{dH}_{2} \mathrm{O}\right) 1.0 \mathrm{ml}, \mathrm{K}_{2} \mathrm{CrO}_{4}\left(1.94 \mathrm{gl}{ }^{-1}\right.$ $\left.\mathrm{dH}_{2} \mathrm{O}\right) 1.0 \mathrm{ml}$.

F/2 vitamin solution. Thiamine- $\mathrm{HCl}$ add $200 \mathrm{mg}$ powder $\mathrm{l}^{-1}$, Biotin add $10 \mathrm{mll}^{-1}$ of a $0.1 \mathrm{gl}^{-1}$ stock, Cyanocobalamin add $1 \mathrm{mll}^{-1}$ of a $1 \mathrm{gl}^{-1}$ stock.

Thalassiosira pseudonana (Hustedt) Hasle et Heimdal (clone CCMP 1335) from the Provasoli Guillard NCMA (National Center for Marine Algae and microbiota, Maine, USA) were grown between 18 and $22^{\circ} \mathrm{C}$, using $0.2 \mu \mathrm{m}$ filtered and boiled nutrient-poor seawater (Scripps pier, La Jolla, California: lat-long N 32.86671 and W 117.25587, collected on 4 April 2014) with metals and vitamins added to achieve $\mathrm{f} / 2$ trace element concentrations ${ }^{40}$. Phosphate was supplied as $25 \mu \mathrm{M}$, silicate was provided at $100 \mu \mathrm{M}\left(\mathrm{Na}_{2} \mathrm{SiO}_{3} 9 \mathrm{H}_{2} \mathrm{O}\right)$ and nitrogen was supplied as a mixture of $200 \mu \mathrm{M}$ ammonium chloride $\left(\mathrm{NH}_{4} \mathrm{Cl}\right)$ plus $200 \mu \mathrm{M}$ sodium nitrate $\left(\mathrm{NaNO}_{3}\right)$. Cultures were illuminated on a light/dark cycle of $16 / 8 \mathrm{~h}$ with cool white fluorescent lamps (Vita-Lite $5500 \mathrm{~K}$, DUROTEST, USA) at photon flux densities between 80 and $130 \mu \mathrm{E} \mathrm{m}^{-2} \mathrm{~s}^{-1}$. T. pseudonana cell plating was conducting using three-fourth of the seawater media described above, plus one-fourth double distilled water and $8 \mathrm{gl}^{-1}$ of bactoagar (Sigma).

DNA isolation. Plasmid DNA was isolated using the modified alkaline lysis protocol described below. Steps 1-3 are variable depending on the species, while steps 4-10 are common for all species.

Steps 1-3 for S. cerevisiae. (1) Yeast culture (5-10 ml) was grown to high density. (2) Next yeast cells were pelleted at $3,000 \mathrm{~g}$ for $5 \mathrm{~min}$ and supernatant was discarded. (3) Cells were resuspended in $250 \mu \mathrm{l}$ resuspension buffer, which contained $240 \mu \mathrm{l}$ P1 (Qiagen), $5 \mu \mathrm{l}$ of $1.4 \mathrm{M} \beta$-Mercaptoethanol and $5 \mu \mathrm{l}$ Zymolyase solution (Zymolyase solution: $200 \mathrm{mg}$ Zymolyase $20 \mathrm{~T}$ (USB), $9 \mathrm{ml} \mathrm{H}_{2} \mathrm{O}, 1 \mathrm{ml} 1 \mathrm{M}$ Tris pH7.5, $10 \mathrm{ml} \mathrm{50 \%} \mathrm{glycerol,} \mathrm{stored} \mathrm{at}-20^{\circ} \mathrm{C}$ ) and incubated at $37^{\circ} \mathrm{C}$ for $60 \mathrm{~min}$.

Steps 1-3 for P. tricornutum and T. pseudonana. (1) Cultures (10-20 ml) were harvested during exponential growth phase. (2) Cells were pelleted at $4,000 \mathrm{~g}$ for $5 \mathrm{~min}$, supernatant was discarded. (3) Cells were resuspended in $250 \mu \mathrm{l}$ resuspension buffer, which contained $235 \mu \mathrm{l}$ P1 (Qiagen), $5 \mu$ l hemicellulase $100 \mathrm{mg} \mathrm{ml}^{-1}, 5 \mu \mathrm{l}$ of lysozyme $25 \mathrm{mg} \mathrm{ml}^{-1}$, and $5 \mu \mathrm{l} \mathrm{Zymolyase} \mathrm{solution}$

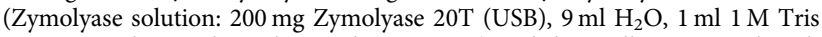
pH7.5, $10 \mathrm{ml} 50 \%$ glycerol, stored at $-20^{\circ} \mathrm{C}$ ) and then cells were incubated at $37^{\circ} \mathrm{C}$ for $30 \mathrm{~min}$.

Steps 1-3 for E. coli. (1) Two ml overnight cultures were used to inoculate $25 \mathrm{ml}$ LB median containing appropriate antibiotic and induction solution (Epicentre) and grown for $4-5 \mathrm{~h}$ in $37^{\circ} \mathrm{C}$ shaker. (2) Next E. coli cells were pelleted at $4,000 \mathrm{~g}$ for $5 \mathrm{~min}$, supernatant was discarded. (3) Cells were resuspended in $250 \mu \mathrm{l}$.

Steps 4-10 common for all species. (4) Two hundred and fifty $\mu \mathrm{l}$ lysis buffer P2 (Qiagen) was added and samples were inverted 5-10 times to mix. (5) Then $250 \mu \mathrm{l}$ of Neutralization buffer P3 was added and samples were inverted 5-10 times to mix. (6) Then samples were spun down at $16,000 \mathrm{~g}, 10 \mathrm{~min}$. (7) Supernatant was transferred to a clean tube and $750 \mu \mathrm{l}$ isopropanol was added and the samples were mixed by inversion and spun down at $16,000 g, 10 \mathrm{~min}$. (8) Next the supernatant was removed and $750 \mu \mathrm{l} 70 \% \mathrm{EtOH}$ was added and samples were mixed by inversion and span down at $16,000 \mathrm{~g}, 5 \mathrm{~min}$. (9) Next the supernatant was discarded and pellets were resuspended in 50-100 $\mu$ of TE buffer. (10) After that the samples were kept at $37^{\circ} \mathrm{C}$ for $30-60 \mathrm{~min}$ to dissolve.

Transfer of DNA into P. tricornutum by electroporation. Culture $(200 \mathrm{ml})$ in exponential phase (bulk florescence $=50$ ) was centrifuged at $3,000 \mathrm{~g}$ for $5 \mathrm{~min}$. Supernatant was removed, cells were resuspended in $1 \mathrm{ml}$ of $0.5 \mathrm{M} \mathrm{NaCl}, 50 \mathrm{mM}$ mannitol and centrifuged at $3,000 \mathrm{~g}$ for $5 \mathrm{~min}$. Next the supernatant was removed and cells were resuspended in $1 \mathrm{ml}$ of $1 \mathrm{M}$ Sorbitol. Next $400 \mu \mathrm{l}$ of cells were removed and mixed with $10 \mu \mathrm{l}$ plasmid DNA $\left(\sim 2 \mu \mathrm{g} \mu \mathrm{l}^{-1}\right)$. The mixture was moved to a $0.2-\mathrm{cm}$ electroporation cuvette (Bio-Rad) and subjected to electroporation at $700 \mathrm{~V}, 200 \Omega, 25 \mu \mathrm{F}$. Then the cells were resuspended in $20 \mathrm{ml}$ of L1 media and grown for 2 days before transfer to selection plates containing phleomycin $\left(20 \mu \mathrm{g} \mathrm{ml}^{-1}\right)$.

PEG DNA transformation method. P. tricornutum cells were grown in L1 liquid medium or on plates. Liquid cultures were spun for $5 \mathrm{~min}$ at $4,000 \mathrm{~g}$ at $10^{\circ} \mathrm{C}$. Supernatant was removed and the cells were counted using a haemocytometer. Next the cells were resuspended to give a final concentration in the range of $3-6 \times 10^{8}$ cells $\mathrm{ml}^{-1}$. For $P$. tricornutum grown on plates, $250 \mu \mathrm{l}$ of $P$. tricornutum culture adjusted to $1.0 \times 10^{8}$ cells ml $^{-1}$ was plated on $1 / 2 \mathrm{~L} 1,1 \%$ agar plates and grown for 4 days, then $500 \mu \mathrm{l}$ of L1 media was added to the plate and cells were scraped to collect. Then cell concentration was adjusted to $3-6 \times 10^{8} \mathrm{cells}^{-1}$. Next $1 \mathrm{ml}$ of cells was resuspended in $9 \mathrm{ml}$ of filter sterilized spheroplasting solution $\left(20 \mu \mathrm{l}\right.$ of Zymolase $100 \mathrm{~T}\left(10 \mathrm{mg} \mathrm{ml}^{-1}\right), 100 \mu \mathrm{l}$ of freshly made lysozyme $\left(25 \mathrm{mg} \mathrm{ml}^{-1}\right), 0.1 \mathrm{~g}$ of hemicellulase and L1 solution was added to final volume of
$9 \mathrm{ml}$ ) and incubated for $30 \mathrm{~min}$ at $37^{\circ} \mathrm{C}$. Next $40 \mathrm{ml}$ of $\mathrm{L} 1$ solution was added and mixed by inverting, followed by centrifugation for $5 \mathrm{~min}$ at $3,000 \mathrm{~g}, 10^{\circ} \mathrm{C}$. Then supernatant was removed and cells were respuspened in $500 \mu \mathrm{l}$ of $\mathrm{L} 1$ media. Spheroplasts $(250 \mu \mathrm{l})$ were transferred to $1.5 \mathrm{ml}$ Eppendorf tube, and $25 \mu \mathrm{l}$ of DNA $\left(\sim 1 \mu \mathrm{g} \mu \mathrm{l}^{-1}\right)$ was added and immediately $1 \mathrm{ml}$ of $25 \%$ PEG $8,000,10 \mathrm{mM}$ Tris $\mathrm{pH}$ $8,10 \mathrm{mM} \mathrm{CaCl} 2,2.5 \mathrm{mM} \mathrm{MgCl}_{2}, \mathrm{pH} 8$ equilibrated at $37^{\circ} \mathrm{C}$ was added and tubes were inverted four to six times. Then the mixture was incubated at room temperature for $10 \mathrm{~min}$. Next the mixture was centrifuged for $7 \mathrm{~min}$ at $1,500 \mathrm{~g}$. Supernatant was removed and cells were resuspended in $30 \mathrm{ml}$ of L1 and incubated for $45 \mathrm{~min}$ without selection at $18^{\circ} \mathrm{C}$. Then the cells were centrifuged for $5 \mathrm{~min}$ at 3,000 r.p.m., $15^{\circ} \mathrm{C}$. Then the cells were resuspended in $600 \mu \mathrm{l}$ of $\mathrm{L} 1$ and $200 \mu \mathrm{l}$ was plated on $1 / 2 \times \mathrm{L} 1,20 \mu \mathrm{g} \mathrm{ml}^{-1}$ chloroamphenicol. After 2 days, the cells were scraped (in $500 \mu \mathrm{l}$ of L1 media) and plated on $0.5 \times \mathrm{L} 1,1 \%$ agar plates containing $20 \mu \mathrm{g} \mathrm{ml}^{-1}$ phleomycin. Colonies appeared after 10-14 days.

Transfer of DNA to P. tricornutum via conjugation from E. coli. Preparation of P. tricornutum cells. Two hundred and fifty $\mu \mathrm{l}$ of liquid grown culture adjusted to $1.0 \times 10^{8}$ cells ml $^{-1}$ was plated on $1 / 2 \mathrm{~L} 1,1 \%$ agar plates and grown for 4 days. Then $500 \mu \mathrm{l}$ of L1 media was added to the plate and cells were scraped and counted using a hemocytometer. Next the concentration was adjusted to $5 \times 10^{8} \mathrm{cells} \mathrm{ml}^{-1}$.

Preparation of E. coli cells. Culture $(50 \mathrm{ml})$ was grown at $37^{\circ} \mathrm{C}$ to $\mathrm{OD}_{600}$ of $0.8-1.0$ then spun down for $10 \mathrm{~min}$ at $3,000 \mathrm{~g}$ and resuspended in $500 \mu \mathrm{l}$ of SOC media.

Conjugation of P. tricornutum with E. coli. P. tricornutum cells $(200 \mu \mathrm{l})$ was moved to a 1.5-ml microfuge tube and then $200 \mu \mathrm{l}$ of $E$. coli cells were added and mixed by pipetting up and down few times. Next the cells were plated on $1 / 2 \times \mathrm{L} 1$, $5 \% \mathrm{LB}, 1 \%$ agar plates and incubated for 90 minutes at $30^{\circ} \mathrm{C}$ in the dark, then moved to $18^{\circ} \mathrm{C}$ in the light and grown for 2 days. After 2 days, $1 \mathrm{ml}$ of L1 media was added to plates and cells were scraped. Two hundred $\mu \mathrm{l}$ of the scraped cells was plated on $1 / 2 \times \mathrm{L} 1$, phleomycin $20 \mu \mathrm{g} \mathrm{ml}^{-1}, 1 \%$ agar plate and incubated at $18^{\circ} \mathrm{C}$ in the light. Colonies appeared after 10-14 days.

Transfer of DNA to T. pseudonana via conjugation from E. coli. Preparation of T. pseudonana cells. Five hundred $\mathrm{ml}$ of liquid grown culture were spun for $5 \mathrm{~min}$ at $4,000 \mathrm{~g}$ at $10^{\circ} \mathrm{C}$, then most of the media were removed, cells were counted using a haemocytometer and the concentration was adjusted to $2 \times 10^{8}$ cells $\mathrm{ml}^{-1}$.

Preparation of E. coli cells. Culture $(150 \mathrm{ml})$ grown at $37^{\circ} \mathrm{C}$ to $\mathrm{OD}_{600}$ of 0.3 was spun down for $10 \mathrm{~min}$ at $3,000 \mathrm{~g}$ and resuspended in $800 \mu \mathrm{l}$ of SOC media.

Conjugation of T. pseudonana with E. coli. T. pseudonana cells $(200 \mu \mathrm{l})$ was moved to $1.5 \mathrm{ml}$ microfuge tube and then $200 \mu \mathrm{l}$ of $E$. coli cells were added and mixed by pipetting up and down a few times. Next the cells were plated on $1 / 2 \times$ T. pseudonana medium, $5 \% \mathrm{LB}, 1 \%$ agar plates and incubated for $90 \mathrm{~min}$ at $30^{\circ} \mathrm{C}$ in the dark, then moved to $18^{\circ} \mathrm{C}$ in the light and grown for $4 \mathrm{~h}$. Then $1 \mathrm{ml}$ of T. pseudonana medium was added to the plate and cells were scraped. Two hundred $\mu \mathrm{l}$ of the scraped cells was plated on $1 / 2 \times T$. pseudonana medium, Nourseothricin $50 \mu \mathrm{g} \mathrm{ml}^{-1}, 1 \%$ agar plate and incubated at $18^{\circ} \mathrm{C}$ in the light. Colonies appeared after 7-14 days.

Isolation and modification of p05210. Plasmids containing one of each of the five fragments were introduced into P. tricornutum. Plasmids containing what we originally thought to be fragment 5 from scaffold 25 were later found to be a concatenation of fragments 1 and 5 after Ion Torrent Sequencing (Supplementary Fig. 1b). Plasmids recovered from P. tricornutum contained either fragment 1 (for example, p0319 or p0521o) or a reduction of fragment 5 (for example, p0524_3 and p0524_4). A plasmid containing fragment 4 was unexpectedly obtained by an unknown mechanism (p0413; Supplementary Fig. 1c). After reintroduction into P. tricornutum, plasmid p0521o was recovered at its identical size while plasmid p0524_4 was further reduced (Supplementary Fig. 1d). After extended maintenance of plasmid p0521o, a spontaneously minimized form was eventually isolated, which we called p0521o-reduced. To facilitate further molecular biology with these plasmids, p0521 and p0521s were created from plasmids p0521o and p0521oreduced using the following procedure. Plasmids p0521o and p0521o-reduced were transformed into yeast using yeast spheroplast transformation and were modified with the URA3 cassette as follows. The URA3 cassette was amplified by PCR with flanking I-SceI and I-CeuI sites and homology added to the ShBle and oriT sequences using primers 0521URA_F and 0521URA_R (Supplementary Table 1). This PCR product was transformed into yeast cells carrying plasmids p0521o and p0521o-reduced using the lithium acetate method to insert the URA3 cassette between the ShBle and the oriT regions generating plasmids p0521 and p0521s (Fig. 1a).

Other plasmid construction. Vectors for cloning each of the large DNA fragments from $P$. tricornutum chromosome 25 were assembled in yeast by cotransforming XhoI-digested template plasmid pBK-RBYV (Supplementary Fig. 9) and two 200-bp PCR-amplified P. tricornutum DNA homology regions corresponding to the two ends of the fragment to be cloned. Each of the 200-bp PCR products contained $25-40$ bp homologies to the vector pBK-RBYV. Primers to create these 200-bp sequences to TAR clone fragments F1 through F5 can be found 
in Supplementary Table 1. Once the cloning vectors were assembled, they were digested with XhoI to open the vector and excise the URA3 cassette allowing for recombination with the digested $P$. tricornutum DNA.

TAR cloning of $P$. tricornutum fragments was based on previously developed protocols ${ }^{41}$. P. tricornutum DNA was first isolated in agarose plugs using the BioRad CHEF Genomic DNA Plug Kit. To prepare the plugs, $50 \mathrm{ml}$ of mid-log phase $\left(10^{8}\right.$ cells $\left.\mathrm{ml}^{-1}\right) P$. tricornutum culture was centrifuged at $1,500 \mathrm{~g}$ for $5 \mathrm{~min}$ at $10^{\circ} \mathrm{C}$. Cells were washed once with $50 \mathrm{ml}$ of $1 \mathrm{M}$ sorbitol and were resuspended in $2 \mathrm{ml}$ of SPEM solution (1 M sorbitol, $10 \mathrm{mM}$ EDTA pH 7.5, $\mathrm{Na}_{2} \mathrm{HPO}_{4} 7 \mathrm{H}_{2} \mathrm{O}$ $\left.\left(2.08 \mathrm{gl}^{-1}\right), \mathrm{NaH}_{2} \mathrm{PO}_{4} \cdot 1 \mathrm{H}_{2} \mathrm{O}\left(0.32 \mathrm{gl}^{-1}\right)\right)$. The cell suspension was incubated for $5 \mathrm{~min}$ at $37^{\circ} \mathrm{C}$ and mixed with an equal volume of $2.0 \%$ low-melting point agarose in $1 \times$ TAE buffer ( $40 \mathrm{mM}$ Tris, $20 \mathrm{mM}$ acetic acid and $1 \mathrm{mM}$ EDTA), which was equilibrated at $50^{\circ} \mathrm{C}$. Aliquots of $100 \mu \mathrm{l}$ were transferred into plug moulds (BioRad, catalogue \#170-3713) and allowed to solidify for $10 \mathrm{~min}$ at $4^{\circ} \mathrm{C}$. Next the plugs were removed from the moulds into a $50-\mathrm{ml}$ conical tube containing $5 \mathrm{ml}$ of protoplasting solution ( $4.56 \mathrm{ml}$ of SPEM solution, $200 \mu \mathrm{L}$ Zymolyase-100T solution $\left(50 \mathrm{mg} \mathrm{ml}^{-1}\right.$ dissolved in $\left.\mathrm{H}_{2} \mathrm{O}\right), 200 \mu$ lysozyme $\left(25 \mathrm{mg} \mathrm{ml}^{-1}\right), 40 \mu \mathrm{l} \beta$ -

Mercaptoethanol and incubated for $1 \mathrm{~h}$ at $37^{\circ} \mathrm{C}$. Next the plugs were washed with $25 \mathrm{ml}$ of wash buffer ( $20 \mathrm{mM}$ Tris, $50 \mathrm{mM}$ EDTA, $\mathrm{pH} 8.0)$ and then incubated in $5 \mathrm{ml}$ in Proteinase $\mathrm{K}$ buffer (100 mM EDTA (pH 8.0), $0.2 \%$ sodium deoxycholate and $1 \%$ sodium lauryl sarcosine, $1 \mathrm{mg} \mathrm{ml}^{-1}$ Proteinase $\mathrm{K}$ ) for $24 \mathrm{~h}$ at $50{ }^{\circ} \mathrm{C}$. After proteinase $\mathrm{K}$ treatment, plugs were washed four times in wash buffer and stored at $4{ }^{\circ} \mathrm{C}$.

Agarose plugs containing P. tricornutum DNA were digested with AscI, washed in TE buffer ( $\mathrm{pH} 8$ ) and melted in $100 \mu \mathrm{l} \mathrm{TE}$ buffer at $65^{\circ} \mathrm{C}$ for $10 \mathrm{~min}$. The molten agarose was then equilibrated at $42{ }^{\circ} \mathrm{C}$ for $10 \mathrm{~min}$ and $2 \mu \mathrm{l}$ of $\beta$-agarase (NEB) was added and incubated for $8 \mathrm{~h}$. Ten $\mu \mathrm{l}$ of DNA from plugs, (typically $100 \mathrm{ng} \mu \mathrm{l}^{-1}$ ) was mixed with $300-500 \mathrm{ng}$ of vector and the assembly was performed by mixing the DNA with yeast spheroplasts ${ }^{42}$ and plating on complete minimal medium lacking histidine.

Plasmids based on p0521s were constructed using yeast assembly as described above for TAR cloning of P. tricornutum fragments F1 through F5 (ref. 41). For example, a 48,602-bp region from Synechococcus elongatus PCC 7942

(chromosome coordinates 223,718 to 272,317 ) was TAR cloned from previously cloned BAC DNA (previously cloned as fragment 3 (ref. 29)) after digest of BAC DNA with the restriction enzyme FseI. A cloning vector with 200-bp homology regions was prepared as described above (see Supplementary Table 1 for primer sequences). Three regions of the S. elongatus insert were checked by multiplex PCR (see Supplementary Table 1 for sequences) and plasmids were analysed by agarose gel electrophoresis to confirm that they had the correct size.

The pPtPuc plasmids to test the relative importance of the P. tricornutumderived sequences and yeast-derived sequences were constructed as follows. First, a version of pUC19 was constructed containing the transfer origin (oriT) from pRL2948a (originally derived from conjugative plasmid RK2, C. P. Wolk, unpublished data). This region was PCR amplified with primers Puc-oriT-1 and Puc-oriT-2 and cloned into NdeI and SfoI sites of pUC19 within the lacZ alpha region using Gibson assembly to make pUC-oriT. Next, plasmid pUC-oriT was modified with the kanamycin-resistance cassette inserted into the ampicillin cassette to make plasmid pUC-oriT-Km. The kanamycin-resistance cassette was amplified from pACYC177 using primers Puc-oriT-km1 + Puc-oriT-km2 in the ScaI-digested pUC-oriT plasmid. To make plasmids pPtPucl through pPtPuc4, plasmid pUC-oriT-Km was digested with EcoRI and BamHI at the multiple cloning site and assembled with inserts as described below. Templates for PCR amplification of inserts include pAF6 (ref. 43) for PtShBle, p0521s for the $P$. tricornutum region and pCC1BAC-LCYEAST ${ }^{44}$ for the CEN6-ARSH4-HIS3 region.

For pPtPuc1, PtShBle was amplified with primers PtPucla + PtPuc12e, the P. tricornutum region was amplified with primers $\mathrm{PtPuc} 2 \mathrm{~b}+\mathrm{PtPuc} 13 \mathrm{f}$ and the CEN-ARS-HIS region was amplified with primers PtPuc3c + PtPucl4d. For pPtPuc2, PtShBle was amplified with primers PtPucla + PtPuc12e, and the $P$. tricornutum region was amplified with primers $P t P u c 2 b+P t P u c 5 d$. For pPtPuc3, PtShBle was amplified with primers PtPucla + PtPuc15f, and the CEN6-ARSH4-HIS3 region was amplified with primers PtPuc6c + PtPuc14d. For pPtPuc4, PtShBle was amplified with primers PtPucla + PtPuc7d.

A fifth plasmid, pPtPuc7, was constructed containing the ShBle coding region regulated by Cylindrotheca fusiformis promoter and terminator (CfShBle $)^{45}$ and the CEN6-ARSH4-HIS3. Thus, this plasmid contained no P. tricornutum sequence and was assembled by amplifying the CfShBle with primers PtPuc8a + PtPucl7f and the CEN6-ARSH4-HIS3 region with primers PtPuc10c + PtPuc14d.

To make the fluorescent protein translational fusion expression vectors, expression cassettes consisting of a promoter, a fluorescent protein by itself or fused in frame to a protein of known localization and a terminator were first assembled in pUC19 vectors. For pXFP11, the P. tricornutum nitrate reductase promoter (Protein ID 54983) was amplified from P. tricornutum genomic DNA using primers NewXFP1 + NewXFP12, the green fluorescent protein (GFP) gene was amplified using primers NewXFP13 + NewXFP14, and nitrate reductase terminator was amplified from $P$. tricornutum genomic DNA using primers NewXFP15 + NewXFP16. These three PCR products were purified using the QIAquick PCR purification kit (Qiagen) and assembled into an EcoRI- and HindIII-digested pUC19 plasmid using Gibson Assembly. The cassette was then reamplified with primers YeastXFPF4 + YeastXFPR2 and assembled into p0521s using yeast assembly.
To make a mitochondrion-localized fluorescent protein fusion expression cassette, the mitochondrial urea transporter (Protein ID 39772) was amplified from P. tricornutum genomic DNA using primers NewXFP11 + HA-MTUT-YFPTerm- 4 omitting the stop codon. YFP was amplified using primers Fcp-MtUTYFP-Term-5 + HA-MtUT-YFP-Term-6. Regulation for this cassette was provided by the FcpB promoter amplified from P. tricornutum using primers

NewXFP9 + NewXFP10 and the FcpA terminator using primers HA-MtUT-YFPTerm-7 + HA-MTUT-YFP-Term-8. These four PCR products were purified using the QIAquick PCR purification kit (Qiagen) and assembled into an EcoRI- and HindIII-digested pUC19 plasmid using Gibson Assembly. The cassette was then amplified using primers YeastXFPF5 + YeastXFPR1 and assembled into p0521s using yeast assembly.

To make pXFP3, the cassette consisting of FcpB promoter, the $\beta$-carboxyanhydrase open reading frame (Pt protein \#51305) that was translationally fused to cyan fluorescent protein (CFP) and the FcpA terminator was amplified from a previously constructed template plasmid ${ }^{26}$ using primers YeastXFPF2 + YeastXFPR1 and assembled into p0521s using yeast assembly.

The PEPCK from T. pseudonana (protein ID\#5186) was cloned from complementary DNA using the primers Tp-PEPCK-F and Tp-PEPCK-R (Supplementary Table 1), replacing the stop codon with TTA-leucine. The PCR product was then introduced into $\mathrm{pENTR/D/Topo} \mathrm{(Invitrogen)} \mathrm{and} \mathrm{sequenced.}$ PEPCK was then transferred into a custom-built Gateway-compatible destination vector for YFP fusion in carboxyl-terminal (pTpDEST-C'YFP) by LR recombination according to the manufacturer's instructions (Invitrogen). Details of pTpDESTC ${ }^{\prime}$ YFP construction will be described in a forthcoming publication. The plasmid, pTpExpPEPCK-YFP, contained the T. pseudonana-specific nourseothricin resistance marker flanked by the LHCF9 promoter (983-nt upstream of the T. pseudonana protein ID 268127) and the LHCF9 terminator (503-nt downstream of the T. pseudonana protein ID 268127) amplified from $\mathrm{pTpfcp} / \mathrm{nat}^{5}$ followed by the expression cassette composed of the PEPCK-YFP fusion flanked by the LHCF9 promoter and terminator. The junction between PEPCK and YFP was checked by sequencing to ensure in frame cloning. Finally, the 6,377-bp region containing the resistance cassette and the expression cassette was reamplified using the primers Tpconj-F1 and Tpconj-R1 and assembled into the p0521S-URA by yeast recombination as described above to give the final vector p0521-Tp-PEPCK-YFP.

Sequence analysis of plasmids passaged through $\boldsymbol{P}$. tricornutum. Plasmids isolated from P. tricornutum colonies transformed with plasmids containing large fragments of scaffold 25 (Supplementary Fig. 1) were transformed to E. coli and purified from agarose gels by RECO chips (Takara). Sequencing libraries were prepared for each plasmid for the Ion Torrent platform using the Ion Xpress Plus gDNA Fragment Library Kit (Life Technologies). Samples were barcoded, pooled and sequencing on an Ion Torrent 314 chip. Reads were mapped to the $P$. tricornutum genome using CLC Genomics Workbench and visualized using GenomeView ${ }^{46}$. Plasmid p0521s was sequenced after purification using the QIAprep kit using primers Seq0521smallF, Seq0521smallR, Seq0521smallF2, Seq0521smallF3, Seq0521smallF4 and Seq0521smallR2.

Calculation of segregation efficiency for p0521s. Segregation efficiency ( $\left.S_{\text {eff }}\right)$ was calculated according to the following equation ${ }^{47}$ :

$$
S_{\text {eff }}=\left(P_{\text {phleo }} / 100\right)^{1 / n}
$$

In this calculation, $P_{\text {phleo }}$ is the percentage of phleomycin-resistant colonies in cultures passaged without selection and $n$ is the number of nuclear division cycles estimated to have occurred during that time. To calculate $S_{\text {eff }}$ for p0521s maintenance in P. tricornutum, a value of 30 was used for the variable $n$ and the average $P_{\text {phleo }}$ of 35 was used to arrive at an $S_{\text {eff }}$ of 0.97 .

Quantitative PCR experiments. To create standard templates to calibrate the qPCR experiments, templates for each qPCR primer set were assembled onto plasmids. Plasmid pNorm1 was created by amplifying template regions for the yeast HIS3 gene (primers pNorm1-1 and pNorm1-2), the chloramphenicolresistance gene (CmR) from pCC1BAC (primers pNorm1-3 and pNorm1-4), P. tricornutum nitrate reductase (NR, Protein ID 54983, primers pNorm1-5 and pNorm1-6) and P. tricornutum urease gene (Ure, Protein ID 29702, primers pNorm1-7 and pNorm1-8), and assembling them into an EcoRI- and HindIIIdigested pUC19 vector using Gibson assembly. Plasmid pNorm2 was created by first amplifying template regions for $P$. tricornutum $\mathrm{RuBisCO}$ small subunit located on the chloroplast chromosome (RbcS) (primers pNorm2-1 and pNorm2-2) and for P. tricornutum cytochrome B located on the mitochondrion chromosome (CytB) (primers pNorm2-3 and pNorm2-4). These amplified products were assembled into an EcoRI- and HindIII-digested pUC19 vector using Gibson assembly. Plasmids pNorm 1 and pNorm2 were extracted from E. coli using Qiagen QIAprep kit and treated with Plasmid-Safe exonuclease (EpiCentre) to remove any residual genomic DNA. Treated plasmids were extracted twice with phenol:chloroform $^{48}$, precipitated and quantified by Nanodrop (Thermo) to calibrate qPCR standard curves. 
Quantitative PCR analysis was performed using 7900HT Fast Real-Time PCR System (Applied Biosystems) using Fast SYBR Green MasterMix (Applied Biosystems). Reactions consisted of master mix diluted to $1 \times$, plasmid or P. tricornutum genomic extract and $5 \mu \mathrm{M}$ primers in $20 \mu \mathrm{l}$ total volume. To perform qPCR experiments, total DNA was extracted from $P$. tricornutum cells containing plasmid p0521s or pPtPuc3 using a modified CTAB protocol ${ }^{12}$. Standard curves were performed for each primer pair using serial dilutions of pNorm 1 or pNorm2 plasmid, as appropriate. The reactions were cycled under the following conditions: $95^{\circ} \mathrm{C}$ for $20 \mathrm{~s}, 40$ cycles of $95^{\circ} \mathrm{C}$ for $1 \mathrm{~s}$ followed by $60^{\circ} \mathrm{C}$ for 20 s during which data were collected. Ct values were calculated by the SDS software, plotted as a function of number of template molecules and fit to a logarithmic trend line. Curves were linear over at least four orders of magnitude. Three biological replicates (plasmids extracted from different $P$. tricornutum strains containing plasmid) were tested, each with two to four technical replicates at each dilution. $\mathrm{Ct}$ values resulting from experimental samples were used to calculate the number of molecules of template molecule in the qPCR reaction. The experiment was repeated at least twice for both p0521s and pPtPuc3 plasmids.

Plasmid-safe experiments. Plasmids from $P$. tricornutum lines containing the p0521s plasmid were extracted using the modified alkaline lysis extraction protocol described above. A $2 \times 2$ factorial experimental design was set up to test the effects of restriction digest and exonuclease treatment on the ability of plasmids extracted from $P$. tricornutum to transform E. coli. First, ClaI restriction digest or mock reaction was performed on samples using $1-2 \mu \mathrm{g}$ total DNA in a $100-\mu \mathrm{l}$ total reaction with $1 \times$ CutSmart buffer and ClaI (NEB) or water in digested or mockdigested samples, respectively. Reactions were incubated for $1 \mathrm{~h}$ at $37^{\circ} \mathrm{C}$. To each $100 \mu \mathrm{l}$ digest or mock digest, $10 \mu \mathrm{l}$ Plasmid-Safe reaction buffer was added and $8 \mu \mathrm{l}$ ATP solution and $3 \mu$ l Plasmid-safe exonuclease or water (mock) to a final volume of $200 \mu \mathrm{l}$. The reactions were incubated at $37^{\circ} \mathrm{C}$ for $1 \mathrm{~h}$. Finally, the reactions were incubated at $70^{\circ} \mathrm{C}$ for $1 \mathrm{~h}$ to inactivate the enzymes. Treated DNA was precipitated, resuspended in water and transformed into E. coli strain Epi300.

Southern blot. For Southern blot analysis of P. tricornutum genomic DNA from lines containing the p0521s plasmid, DNA was extracted using a modified CTAB protocol $^{12}$ from $P$. tricornutum cultures grown on L1 agar containing phleomycin $\left(20 \mu \mathrm{g} \mathrm{ml}^{-1}\right)$. DNA $(\sim 30 \mu \mathrm{g})$ was digested with ClaI that cuts a single time within the p0521s plasmid and still cuts frequently within the P. tricornutum genome. Plasmid control DNA from E. coli was digested with RsrII that also cuts a single time within the p0521s sequence but is not affected by Dam methylation. Digested DNA was separated by agarose gel electrophoresis overnight at $0.1 \mathrm{~V} \mathrm{~cm}^{-1}$ in a $1 \%$ gel. Gels were treated for Southern blot by rinsing once in $0.25 \mathrm{M} \mathrm{HCl}$, twice in denaturing solution $(1.5 \mathrm{M} \mathrm{NaCl}, 0.5 \mathrm{M} \mathrm{NaOH})$ and twice in neutralization solution ( $1.5 \mathrm{M} \mathrm{NaCl}, 0.5 \mathrm{M}$ Tris, $\mathrm{pH} 7.0)$. Overnight transfers onto Hybond $\mathrm{N}+$ membrane (GE) were performed in $20 \times$ saline-sodium citrate $(3 \mathrm{M} \mathrm{NaCl}, 300 \mathrm{mM}$ $\mathrm{Na}_{3} \mathrm{C}_{6} \mathrm{H}_{5} \mathrm{O}_{7}$ ). Hybridization was performed using a probe to the ShBle cassette constructed by the DIG PCR Probe Synthesis Kit (Roche) according to the manufacturer's instruction using primers SB2 and 3'ShBle (Supplementary Table 1). Blots were developed using the bioluminescent substrate CDP-star and imaged on the C-DiGit chemiluminescent scanner (Licor).

Laser scanning confocal microscopy. A Leica TCS SP5 confocal laser scanning microscope equipped with a $\times 100$ oil immersion objective was used to visualize the fluorescently tagged proteins. CFP, GFP and YFP were excited with 458, 488 and $514 \mathrm{~nm}$ lasers, with emission monitored at $470-520$ (CFP), $505-530 \mathrm{~nm}$ (GFP) and 525-560 nm (YFP). Autoflourescence of the plastid was monitored at $700-740 \mathrm{~nm}$.

SEM microscopy-sample preparation protocol. Cells were spun at room temperature for $4 \mathrm{~min}$ at $2,000 \mathrm{~g}$ to produce a loose pellet. Media $(950 \mu \mathrm{l})$ were removed and replaced with $1 \mathrm{ml}$ of fixative. The fixative solution was $2.5 \%$ glutaraldehyde, $100 \mathrm{mM}$ sodium cacodylate, $2 \mathrm{mM}$ calcium chloride and $2 \%$ sucrose (fixative was added cold and samples were stored at $4{ }^{\circ} \mathrm{C}$ ). Cells were immobilized on polyethylenimine or poly-D-lysine coated ITO glass coverslips for $2 \mathrm{~min}$ and washed in $0.1 \mathrm{M}$ cacodylate buffer with $2 \mathrm{mM}$ calcium chloride and $2 \%$ sucrose for $5 \times 2 \mathrm{~min}$ on ice. Cells were post fixed in $2 \%$ osmium tetoxide with $2 \%$ sucrose in $0.1 \mathrm{M}$ cacodylate for $30 \mathrm{~min}$ on ice. Cells were rinsed in double distilled water and dehydrated in an ethanol series $(20,50,70,100 \%)$ for $2 \mathrm{~min}$ each on ice. Samples were critical point dried (with $\mathrm{CO}_{2}$ ) and sputter-coated with a thin layer of $\mathrm{Au} / \mathrm{Pd}$. Samples were imaged with a Zeiss Merlin Fe-SEM at $2.5 \mathrm{kev}, 83 \mathrm{pA}$ probe current and $2.9 \mathrm{~mm}$ working distance (zero tilt) using the in-lens SE detector.

\section{References}

1. Bozarth, A., Maier, U.-G. \& Zauner, S. Diatoms in biotechnology: modern tools and applications. Appl. Microbiol. Biotechnol. 82, 195-201 (2009).

2. Hildebrand, M., Davis, A. K., Smith, S. R., Traller, J. C. \& Abbriano, R. The place of diatoms in the biofuels industry. Biofuels 3, 221-240 (2012).

3. Nelson, D., Tréguer, P., Brzezinski, M., Leynaert, A. \& Queguiner, B. Production and dissolution of biogenic silica in the ocean: revised global estimates, comparison with regional data and relationship to biogenic sedimentation. Glob. Biogeochem. Cycle 9, 359-372 (1995).

4. Dunahay, T. G., Jarvis, E. E. \& Roessler, P. G. Genetic transformation of the diatoms Cyclotella cryptica and Navicula saprophila. J. Phycol. 31, 1004-1012 (1995).

5. Poulsen, N., Chesley, P. M. \& Kröger, N. Molecular genetic manipulation of the diatom Thalassiosira pseudonana (Bacillariophyceae). J. Phycol. 42, 1059-1065 (2006).

6. Apt, K. E., Kroth-Pancic, P. G. \& Grossman, A. R. Stable nuclear transformation of the diatom Phaeodactylum tricornutum. Mol. Gen. Genet. 252, 572-579 (1996)

7. Miyagawa, A. et al. Research note: high efficiency transformation of the diatom Phaeodactylum tricornutum with a promoter from the diatom Cylindrotheca fusiformis. Phycol. Res. 57, 142-146 (2009).

8. Falciatore, A., Casotti, R., Leblanc, C., Abrescia, C. \& Bowler, C. Transformation of nonselectable reporter genes in marine diatoms. Mar. Biotechnol. 1, 239-251 (1999).

9. Jacobs, J. D. et al. Characterization of two circular plasmids from the marine diatom Cylindrotheca fusiformis: plasmids hybridize to chloroplast and nuclear DNA. Mol. Gen. Genet. 233, 302-310 (1992).

10. Hildebrand, M. et al. Plasmids in diatom species. J. Bacteriol. 173, 5924-5927 (1991).

11. Daboussi, F. et al. Genome engineering empowers the diatom Phaeodactylum tricornutum for biotechnology. Nat. Commun. 5, 3831 (2014).

12. Weyman, P. D. et al. Inactivation of Phaeodactylum tricornutum urease gene using transcription activator-like effector nuclease-based targeted mutagenesis. Plant Biotechnol. J. (2014) doi:10.1111/pbi.12254.

13. Heinemann, J. A. \& Sprague, Jr. G. F. Bacterial conjugative plasmids mobilize DNA transfer between bacteria and yeast. Nature 340, 205-209 (1989).

14. Waters, V. L. Conjugation between bacterial and mammalian cells. Nat. Genet 29, 375-376 (2001)

15. Schröder, G., Schuelein, R., Quebatte, M. \& Dehio, C. Conjugative DNA transfer into human cells by the VirB/VirD4 type IV secretion system of the bacterial pathogen Bartonella henselae. Proc. Natl Acad. Sci. USA 108, 14643-14648 (2011).

16. Sikorski, R., Michaud, W., Levin, H., Boeke, J. \& Hieter, P. Trans-kingdom promiscuity. Nature 345, 581-582 (1990).

17. Strand, T. A., Lale, R., Degnes, K. F., Lando, M. \& Valla, S. A new and improved host-independent plasmid system for RK2-based conjugal transfer. PLoS ONE 9, e90372 (2014)

18. Clarke, L. \& Carbon, J. Isolation of a yeast centromere and construction of functional small circular chromosomes. Nature 287, 504-509 (1980).

19. Stinchcomb, D. T., Struhl, K. \& Davis, R. W. Isolation and characterisation of a yeast chromosomal replicator. Nature 282, 39-43 (1979).

20. Sullivan, B. A., Blower, M. D. \& Karpen, G. H. Determining centromere identity: cyclical stories and forking paths. Nat. Rev. Genet. 2, 584-596 (2001)

21. Obado, S. O., Bot, C., Nilsson, D., Andersson, B. \& Kelly, J. M. Repetitive DNA is associated with centromeric domains in Trypanosoma brucei but not Trypanosoma cruzi. Genome Biol. 8, R37 (2007).

22. Iwanaga, S. et al. Functional identification of the Plasmodium centromere and generation of a Plasmodium artificial chromosome. Cell Host Microbe 7, 245-255 (2010).

23. Miyahara, M., Aoi, M., Inoue-Kashino, N., Kashino, Y. \& Ifuku, K. Highly efficient transformation of the diatom Phaeodactylum tricornutum by multi-pulse electroporation. Biosci. Biotechnol. Biochem. 77, 874-876 (2013).

24. Elhai, J. \& Wolk, C. P. Conjugal transfer of DNA to cyanobacteria. Methods Enzymol. 167, 747-754 (1988).

25. Oakley, K. E. Molecular Mechanisms of Urea Uptake in Marine Diatoms (Univeristy of California, 2010; Available at $<$ http://www.escholarship.org/uc/ item/9mr9p5gv >

26. Hopkinson, B. M., Dont, C. L., Allen, A. E. \& Morel, F. M. M. Efficiency of the CO2-concentrating mechanism of diatoms. Proc. Natl Acad. Sci. USA 108, 3830-3837 (2011).

27. Tanaka, R., Kikutani, S., Mahardika, A. \& Matsuda, Y. Localization of enzymes relating to $\mathrm{C} 4$ organic acid metabolisms in the marine diatom, Thalassiosira pseudonana. Photosynth. Res. 121, 251-263 (2014).

28. Smith, S. R., Abbriano, R. M. \& Hildebrand, M. Comparative analysis of diatom genomes reveals substantial differences in the organization of carbon partitioning pathways. Algal Res. 1, 2-16 (2012).

29. Noskov, V. N. et al. Assembly of large, high G + C bacterial DNA fragments in yeast. ACS Synth. Biol. 1, 267-273 (2012).

30. Gibson, D. G. in Current protocols in molecular biology. (ed. Ausube, F. M.) Chapter 3, Unit 3.22 (John Wiley \& Sons, Inc., 2011).

31. Gibson, D. G. et al. Enzymatic assembly of DNA molecules up to several hundred kilobases. Nat. Methods 6, 343-345 (2009).

32. Maruyama, S. et al. Centromere structures highlighted by the $100 \%$-complete Cyanidioschyzon merolae genome. Plant Signal. Behav. 3, 140-141 (2008). 
33. Inomata, K., Nishikawa, M. \& Yoshida, K. The yeast Saccharomyces kluyveri as a recipient eukaryote in transkingdom conjugation: behavior of transmitted plasmids in transconjugants. J. Bacteriol. 176, 4770 (1994).

34. Archibald, J. M. The puzzle of plastid evolution. Curr. Biol. 19, R81-R88 (2009).

35. Armbrust, E. V. et al. The genome of the diatom Thalassiosira pseudonana: ecology, evolution, and metabolism. Science 306, 79-86 (2004).

36. Bowler, C. et al. The Phaeodactylum genome reveals the evolutionary history of diatom genomes. Nature 456, 239-244 (2008).

37. Palenik, B., Ren, Q., Tai, V. \& Paulsen, I. T. Coastal Synechococcus metagenome reveals major roles for horizontal gene transfer and plasmids in population diversity. Environ. Microbiol. 11, 349-359 (2009).

38. Ma, Y., Paulsen, I. T. \& Palenik, B. Analysis of two marine metagenomes reveals the diversity of plasmids in oceanic environments. Environ. Microbiol. 14, 453-466 (2012).

39. Dupont, C. L. et al. Genomes and gene expression across light and productivity gradients in eastern subtropical Pacific microbial communities. ISME J. 1-17 (2014); doi:10.1038/ismej.2014.198.

40. Guillard, R. R. L. \& Ryther, J. H. Studies of marine planktonic diatoms. I. Cyclotella nana Hustedt, and Detonula confervacea (cleve) Gran. Can. J. Microbiol. 8, 229-239 (1962).

41. Karas, B. J. et al. Assembly of eukaryotic algal chromosomes in yeast. J. Biol. Eng. 7, 30 (2013).

42. Kouprina, N. \& Larionov, V. Selective isolation of genomic loci from complex genomes by transformation-associated recombination cloning in the yeast Saccharomyces cerevisiae. Nat. Protoc. 3, 371-377 (2008).

43. Zaslavskaia, L., Lippmeier, J., Kroth, P. G., Grossman, A. R. \& Apt, K. E. Transformation of the diatom Phaeodactylum tricornutum (Bacillariophyceae) with a variety of selectable marker and reporter genes. J. Phycol. 386, 379-386 (2000).

44. Gibson, D. G. et al. Creation of a bacterial cell controlled by a chemically synthesized genome. Science 329, 52-56 (2010).

45. Poulsen, N. \& Kröger, N. A new molecular tool for transgenic diatoms: control of mRNA and protein biosynthesis by an inducible promoter-terminator cassette. FEBS J. 272, 3413-3423 (2005).

46. Abeel, T., Van Parys, T., Saeys, Y., Galagan, J. \& Van de Peer, Y. GenomeView: a next-generation genome browser. Nucleic Acids Res. 40, e12 (2012).

47. Iwanaga, S., Kato, T., Kaneko, I. \& Yuda, M. Centromere plasmid: a new genetic tool for the study of Plasmodium falciparum. PLoS ONE 7, e33326 (2012).

48. Sambrook, J., Fritsch, E. F. \& Maniatis, T. Molecular Cloning: A Laboratory Manual. Cold Spring Harbor Laboratory 3, 2344Cold Spring Harbor Laboratory Press (2001).

\section{Acknowledgements}

The study was funded by Synthetic Genomics Inc., the United States Department of Energy Genomics Science Program (DE-SC0008593 to C.L.D. and A.E.A.) and Gordon and Betty Moore Foundation (GBMF3828) grants to A.E.A. B.J.K. was supported in part by a fellowship from the National Sciences and Engineering Research Council of Canada.

\section{Author contributions}

B.J.K. discovered the first replicating plasmids in P. tricornutum (p0521 and p0521s), discovered conjugation and PEG-mediated transformation methods in P. tricornutum, optimized conjugation methods and tested plasmid components responsible for episome replication. R.E.D. developed optimized diatom conjugation methods and tested plasmid components responsible for episome replication. S.C.L. customized p0521s to confer nourseothricin resistance, express YFP-tagged protein in T. pseudonana and established conjugation in this diatom. A.P.R.P., C.M.N., J.K.B., M.H.E., H.O.S., C.A.H., J.I.G., J.C.V., A.E.A., C.L.D. and P.D.W. conceived and designed the additional experiments. J.M., A.P.R.P., C.M.N., J.K.B., T.J.D., J.J., K.B., J.T.F.G. and P.D.W. performed additional experiments. B.J.K., R.E.D., S.C.L., J.M., A.P.R.P., C.M.N., J.K.B., R.E.V., C.L.D. and P.D.W. analysed the data. B.J.K., S.C.L., A.E.A., C.L.D. and P.D.W. wrote the paper.

\section{Additional information}

Supplementary Information accompanies this paper at http://www.nature.com/ naturecommunications

Competing financial interests: J.C.V. is executive chairman and co-chief scientific officer of Synthetic Genomics Inc., H.O.S. is co-chief scientific officer and a member of the board of directors and C.A.H. is chairman of the scientific advisory board. All three of these authors and the J. Craig Venter Institute hold shares of Synthetic Genomics Inc. The remaining authors declare no competing financial interests.

Reprints and permission information is available online at http://npg.nature.com/ reprintsandpermissions/

How to cite this article: Karas, B. J. et al. Designer diatom episomes delivered by bacterial conjugation. Nat. Commun. 6:6925 doi: 10.1038/ncomms7925 (2015).

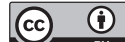

This work is licensed under a Creative Commons Attribution 4.0 International License. The images or other third party material in this article are included in the article's Creative Commons license, unless indicated otherwise in the credit line; if the material is not included under the Creative Commons license, users will need to obtain permission from the license holder to reproduce the material. To view a copy of this license, visit http://creativecommons.org/licenses/by/4.0/ 